\title{
Risky Sexual Behavior and Associated Factors Among Adolescent Students in Tana Haik High School, Bahir Dar, Northern Ethiopia
}

\author{
Hiwot Amare ${ }^{1, ~ *}$, Muluken Azage ${ }^{2}$, Mahider Negash ${ }^{3}$, Abinet Getachew ${ }^{3}$, Adinew Desale ${ }^{1}$, \\ Nardos Abebe ${ }^{1}$ \\ ${ }^{1}$ Ethiopian Public Health Institute, Addis Ababa, Ethiopia \\ ${ }^{2}$ Bahir Dar University, College of Medicine and Health Sciences, Bahir Dar, Ethiopia \\ ${ }^{3}$ Merystopes International MCH Clinic, Bahir Dar, Ethiopia
}

Email address:

hiwotamare22@yahoo.com (H. Amare), mulukeag@yahoo.com (M. Azage), mahiderhiwot@gmail.com (M. Negash), abi7834@gmail.com (A. Getachew), adinewdesale@yahoo.com (A. Desale), nardosabebe799@gmail.com (N. Abebe)

${ }^{*}$ Corresponding author

\section{To cite this article:}

Hiwot Amare, Muluken Azage, Mahider Negash, Abinet Getachew, Adinew Desale, Nardos Abebe. Risky Sexual Behavior and Associated Factors Among Adolescent Students in Tana Haik High School, Bahir Dar, Northern Ethiopia. International Journal of HIV/AIDS Prevention, Education and Behavioural Science. Vol. 3, No. 4, 2017, pp. 41-47. doi: 10.11648/j.ijhpebs.20170304.12

Received: August 4, 2017; Accepted: August 23, 2017; Published: October 17, 2017

\begin{abstract}
Introduction: Adolescence is a period of transition from childhood to adulthood. World Health Organization defines adolescent as the person between 10 and 19 years of age. Adolescents' sexual behavior threatens the physical, psychological, social health and well-being of this group. Therefore, assessing the sexual behavior of adolescent students is essential to evaluate vulnerability and this enables one take appropriate preventive measure. Objective: The objective of this study is to assess the risky sexual behavior of school adolescents and responsible factors influencing their risky sexual behavior practices in Tana Haik Secondary and Preparatory School, Bahir Dar, Northern Ethiopia, 2016. Methods: A crosssectional study was carried out using questionnaire. A systematic random sampling was used to get the total sample size of 308 participants. A pre-tested, structured questionnaire was used to collect quantitative data and Data analysis was done using SPSS version 16.0 software packages. Result: Out of the study participants, $79(26 \%)$ respondents were practiced sexual intercourse. Among the sexually active students $73 \%$ were not utilized condoms, $34 \%$ of them had more than one partner and $5 \%$ reported to have sexual intercourse with commercial sex workers. Personal pressure (46\%), peer pressure (27\%), forced (10\%), alcohol and chat influence $(9 \%)$ and economic problem $(9 \%)$ were the reasons reported for the initiation of the first sexual practice. Fifty-nine (19\%) of the study participants were developed risky sexual behaviors. Participants' educational level, marital status, parental marital status, living status, and alcohol consumption were predictor factors for the existence of different sexual behaviors. Conclusion: A considerable number of school adolescents had started sexual activity early and have practiced risky sexual behavior that might predispose them to different sexual and reproductive health problems. Delay in sex debut and reducing risky sexual behavior among adolescents can be achieved through well designed sexual education programs at the school.
\end{abstract}

Keywords: Risky Sexual Behavior, Associate Factors, School adolescent, Bahir Dar City

\section{Introduction}

Adolescence begins with the onset of physiologically normal puberty and it's a period of development corresponds roughly to the period between the ages of 10 and 19 years [1]. The adolescent is a shift period from childhood to independent adulthood that achieves the highest stage of cognitive and physical development and strives to define their self-identity [2]. A need for independence is also one of the features of this group and most of the young people join the labor force [3].

According to United Nation report, the total number of the 
world population in 2015 is projected to be more than 7.3 billion, of which one-fourth are in the age group of 10-24 [2]. The life of adolescents is at risk for the reason that they do not have adequate information, health services, and support they need to go through sexual development [4]. Adolescents and young adults are frequently changing relationships with opposite sex, highly concerned with physical and sexual good looks. Adolescents are more likely to make decisions about the future without adequately considering the consequences [1].

A study reported that adolescents and young adults were engaged in risky sexual practices that expose for acquiring sexually transmitted infections and unwanted pregnancy. Most of the sexual practices during adolescence period are unsafe due to lack of awareness about sexual and reproductive health, limited access to health services, lack information about contraception and susceptibility to sexual abuse [5]. Therefore, a risk of unnecessary pregnancy, risky abortion and sexually transmitted infections including HIV/AIDS are prevalent among young people [2]. In resource limited countries, nearly half of HIV infections happen in people younger than 25 years old, this implies that nearly $60 \%$ of all new HIV infections are among 15 to 24 years [6].

Sexual beginning among adolescent is linked with divorced families, sexually active friends, illiterate, family instability, low income, tolerant attitudes, and lack of confidence to avoid sex, peer pressure, drinking alcohol, drug use, previous sexual abuse and exposure to sexual content of media [7, 8]. Stigma dampens young people from taking preventive measures against sexually transmitted diseases and informing their sexual partner [9 10]. Adolescents who had sexual practice outside of marriage may face social stigmas, family conflicts, problems with school and the potential need for unsafe abortions along with unintended pregnancy and increased exposure to STIs [11].

Before adolescent become sexually active, necessary facts and information should be provided and strength in school and further than. Preventive methods that enable adolescents to develop safer behavior requires not only just knowing who is at risk, but also understanding why they engage in risky practice, motivating them to reduce their risk, developing their knowledge and skills, and improving their access to means of prevention [12]. Therefore, to equip adolescent on disadvantages of risky sexual behavior high school are the appropriate environment alongside with the formal education.

Sexual and reproductive health services, including risky sexual behavior, have been implemented at each school along with the formal education to internalize what they have been taught on sexual health and risky behaviors among themselves since 2006 [13]. But, there is no recent information on risky sexual behaviors among adolescent high school students after implementation of such youth-friendly sexual and reproductive health services. The finding of the study will help to provide the current status on risky sexual behavior and its associated factors to identify the gaps and strengthen the existing strategies. Therefore, the aim of this study was to assess risky sexual behavior and its associated factors among adolescents in Tana Haik high school.

\section{Methods and Materials}

\subsection{Study Design and Area}

Institutional based cross-sectional study was employed at Tana Haik Secondary and Preparatory School at Bahir Dar, Amhara Region since, February 2016. Bahir Dar is the capital city of the Amhara National Regional State which is located at $565 \mathrm{~km}$ from the northwest direction of Addis Ababa, a capital city of Ethiopia. There are universities, colleges and preparatory schools in the city. TanaHaik secondary and preparatory school is one of them with a total of 3,200 students in 2016 .

\subsection{Study population}

The study population was all adolescent students that attending their education at day time in Tana Haik secondary and preparatory school during the study period. An adolescent whose age is below 14 and above 19 years and that attend his/her education at night time were excluded from the study.

\subsection{Sample Size and Sampling Technique}

The sample size was calculated using the single population proportion formula by considering the following assumptions: the proportion of risky sexual behavior to be $24 \%$ from a previous study [13], 95\% confidence interval, the margin of error $5 \%$ and $10 \%$ non response rate. Then, the final sample size was 308 participants.

A systematic random sampling technique was employed to select a representative sample of adolescent students in each grade. The sample size was distributed proportionally to each grade based on the number of students.

\subsection{Data Collection}

Data were collected using self-administered structured questionnaire. The questionnaire had questions of sociodemographic variables of participants and sexual and behavioral related issues. The questionnaire was initially prepared in English and then translated into Amharic, the local language. Four nursing diploma graduate were recruited as data collection facilitator. The questionnaire was pretested to ensure the understandability of questions by study participants. Data were collected anonymously to ensure confidentiality. The filled questionnaire was checked for completeness and consistency by the principal investigator.

\subsection{Data Analysis}

Data were entered, cleaned and analyzed using SPSS (Statistical Package for Social Sciences) version 16 software. Descriptive statistics were calculated to describe data. Binary and multivariable logistic regression analyses were used to 
determine the presence of statistically significant associations between the outcome and the independent variables. Crude and adjusted odds ratios with $95 \% \mathrm{CI}$ were calculated and a $\mathrm{p}$ value less than 0.05 was considered statistically significant.

\subsection{Ethical Considerations}

The study was approved by Ethical Review Committee of the Amhara Regional Health Bureau. Permission was also secured from Tana Haik secondary and preparatory school director. Informed consent was obtained from each study participants and their parents (for $<16$ years old students). All participants were informed of their right to refuse at any time and not to write their names to ensure confidentiality.

\section{Results}

All adolescent students completed the questionnaire. Of the total participants (308), 151 (51\%) were females and 175 (57\%) were in the age group of 17-19. Above eighty percent of the participants (82\%) were Orthodox Christians and 90\% were Amhara by ethnic group. Above ninety percent (94\%) were single. Sixty percent of the study participants came from the family size of 5 to 7 and $64 \%$ of study participants lived with both parents. Nearly twenty percent $(18 \%)$ of the participants came from the rural area and lived in rented house in the city.

Table 1. The socio-demographic characteristics of school adolescents in Tana Haik Secondary and Preparatory School, February 2016.

\begin{tabular}{|c|c|c|c|}
\hline Variables $(n=308)$ & Male n (\%) & Female $n(\%)$ & Total n (\%) \\
\hline Sex & $151(49)$ & $157(51)$ & $308(100)$ \\
\hline \multicolumn{4}{|l|}{ Age } \\
\hline $14-16$ & $60(45)$ & $73(55)$ & $133(43)$ \\
\hline $17-19$ & $91(52)$ & $84(48)$ & $175(57)$ \\
\hline \multicolumn{4}{|l|}{ Religion } \\
\hline Muslim & $10(42)$ & $14(58)$ & $24(8)$ \\
\hline Orthodox & $117(46)$ & $137(54)$ & $254(82)$ \\
\hline Protestant & $24(80)$ & $6(20)$ & $30(10)$ \\
\hline \multicolumn{4}{|l|}{ Ethnicity } \\
\hline Amhara & $126(45)$ & $152(55)$ & $278(90)$ \\
\hline Others & $25(83)$ & $5(17)$ & $30(10)$ \\
\hline \multicolumn{4}{|l|}{ Education } \\
\hline Grade 9 & $32(38)$ & $53(62)$ & $85(27.6)$ \\
\hline Grade 10 & $45(51)$ & $43(49)$ & $88(28.6)$ \\
\hline Grade 11 & $33(53)$ & $29(47)$ & $62(20)$ \\
\hline \multicolumn{4}{|c|}{ Perceived family economic status relative to neighbor: } \\
\hline Poor & $51(61)$ & $33(39)$ & $84(27)$ \\
\hline Similar & $56(43)$ & $74(57)$ & $130(42)$ \\
\hline Better & $44(47)$ & $50(53)$ & $94(31)$ \\
\hline \multicolumn{4}{|l|}{ Marital Status } \\
\hline Single & $145(50)$ & $145(50)$ & $290(94)$ \\
\hline Married & $6(33)$ & $12(67)$ & $18(6)$ \\
\hline \multicolumn{4}{|l|}{ Family size } \\
\hline$<5$ & $52(56)$ & $41(44)$ & $93(30)$ \\
\hline $5-7$ & $84(46)$ & $100(54)$ & $184(60)$ \\
\hline$>7$ & $15(48)$ & $16(52)$ & $31(10)$ \\
\hline \multicolumn{4}{|l|}{ Family Marital Status } \\
\hline Live together & $109(49)$ & $112(51)$ & $221(72)$ \\
\hline Div/Wid/Sep. & $42(48)$ & $45(52)$ & $87(28)$ \\
\hline \multicolumn{4}{|l|}{ Live with whom } \\
\hline With relatives/friends & $15(41)$ & $22(59)$ & $37(12)$ \\
\hline Alone & $15(48)$ & $16(52)$ & $31(10)$ \\
\hline \multicolumn{4}{|l|}{ Residence Situation } \\
\hline Live in the town & $125(49)$ & $128(51)$ & $253(82)$ \\
\hline Came from rural area and live town & $26(47)$ & $29(53)$ & $55(18)$ \\
\hline \multicolumn{4}{|l|}{ Father's Education: } \\
\hline Illiterate & $24(48)$ & $26(52)$ & $50(16)$ \\
\hline Primary education & $43(44)$ & $55(56)$ & $98(32)$ \\
\hline Secondary and above & $84(53)$ & $76(48)$ & $160(52)$ \\
\hline \multicolumn{4}{|l|}{ Mother's Education: } \\
\hline Illiterate & $31(40)$ & $46(60)$ & $77(25)$ \\
\hline Primary education & $53(52)$ & $49(48)$ & $102(33)$ \\
\hline Secondary and above & $67(52)$ & $62(48)$ & $129(42)$ \\
\hline
\end{tabular}




\subsection{Risky Sexual Behavior of the Study Participants}

Seventy-nine $(26 \%)$ of the participants reported they had experienced sexual practice. Among those who had sexual practice, $20(25 \%)$ were within the age of 14 to 16 years.
Personal pressure $(46 \%)$, peer pressure $(27 \%)$, force $(10 \%)$, alcohol and chat influence $(9 \%)$ and economic problem $(9 \%)$ were the reasons reported for the beginning of the first sexual practice.

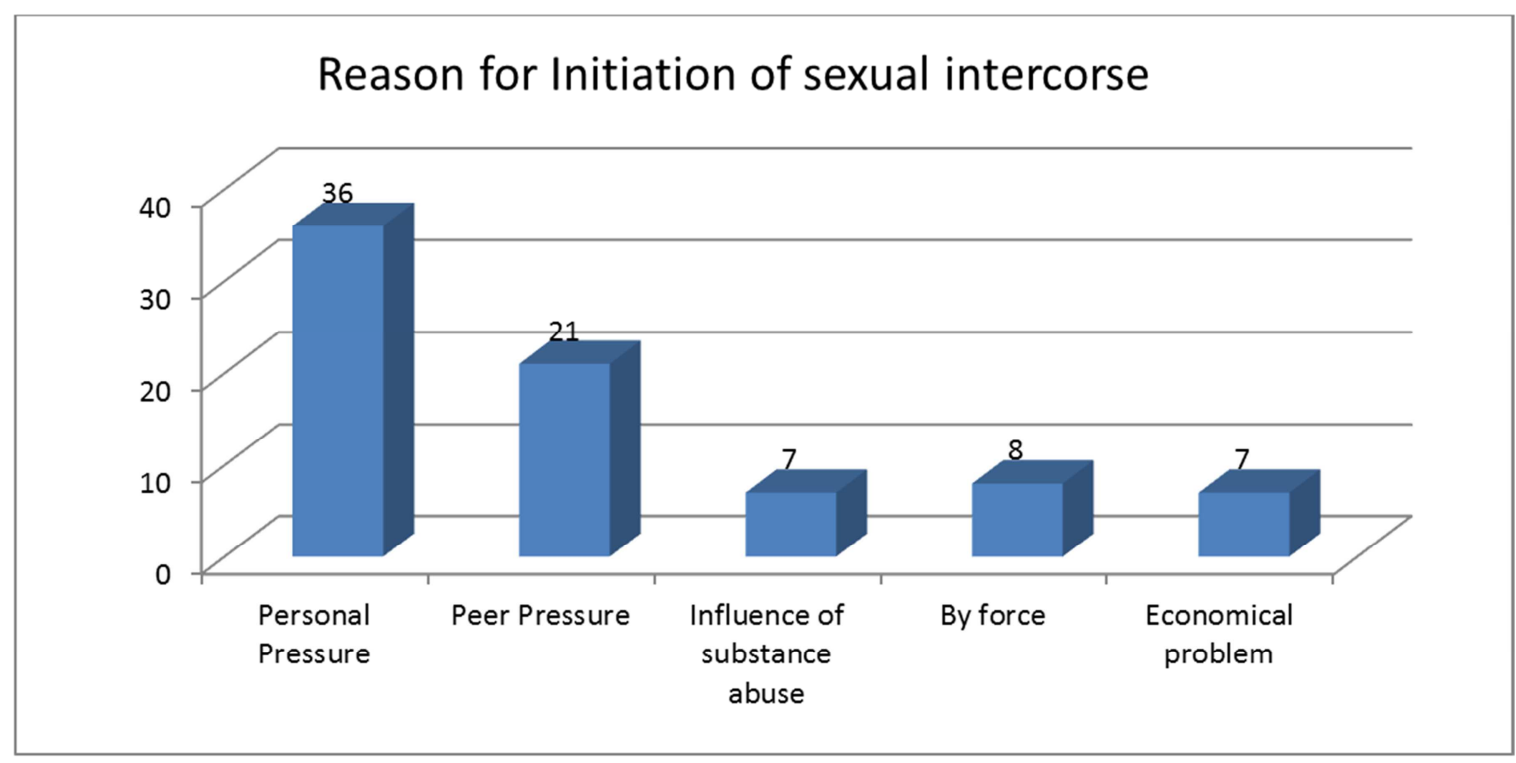

Figure 1. Reasons for initiation of first sexual practice reported by study participants.

Of those having sexual practice, 58 (73\%) did not use condoms (unsafe sex) during the first sexual practice, 27 (34\%) of them had more than one sexual partner and $4(5 \%)$ had sexual intercourse with commercial sex workers. Fiftynine $(19 \%)$ of the study participants had risky sexual behaviors (unsafe sex, sexual intercourse with the commercial-sex worker, sex with more than one partners and sexual intercourse by force).

Table 2. Sexual behavior of school adolescents in TanaHaik Secondary and Preparatory School, February 2016.

\begin{tabular}{lll}
\hline Variables & Frequency & Percent \\
\hline Ever practice sex $(\mathrm{n}=308)$ & 79 & 26 \\
Yes & 229 & 74 \\
No & & \\
Age at first sex (n=79) & 20 & 25 \\
$14-16$ & 59 & 75 \\
$17-19$ & & \\
Reason for Sexual Intercourse (n=79) & 36 & 46 \\
Personal Pressure & 21 & 27 \\
Peer Pressure & 7 & 9 \\
Influence of substance abuse & 8 & 10 \\
By force & 7 & 9 \\
Economical problem & & \\
Condom useduring first sexual intercourse \\
(n=79) & 21 & 27 \\
Yes & 58 & 73 \\
No & & \\
Number of sexual partners (n=79) & 52 & 66 \\
One & 27 & 34 \\
more than one & & \\
Reason for more partner (n=27) & 25 & 93 \\
Sexual pleasure from all & 2 & 7 \\
Perceive all my partners are healthy & & \\
Sexual intercourse with CSW (n=79) & & \\
\hline
\end{tabular}

\begin{tabular}{lll}
\hline Variables & Frequency & Percent \\
\hline Yes & 4 & 5 \\
No & 75 & 95 \\
Sexual intercourse by force $(\mathrm{n}=79)$ & & \\
Yes & 8 & 10 \\
No & 71 & 90 \\
Sex with regular Partner $(\mathrm{n}=79)$ & & \\
Yes & 37 & 47 \\
No & 42 & 53 \\
Risky Sexual Behavior $(\mathrm{n}=308)$ & & \\
Yes & 59 & 19 \\
No & 249 & 81 \\
\hline
\end{tabular}

Among the study subjects $131(42.5 \%), 27(8.7 \%)$ and 2 $(0.6 \%)$ were using alcohol, chat, and hashish ranging from $2-$ 3 times in a month to daily respectively.

Table 3. The magnitude of Substance use among school adolescents in Tana Haik Secondary and Preparatory School, February 2016.

\begin{tabular}{lll}
\hline Variables & Frequency & Percent \\
\hline Alcohol consumption: $\mathrm{n}=308$ & & \\
Never Drunk & 177 & 57.5 \\
Drunk & 131 & 42.5 \\
Khat chewing: $\mathrm{n}=308$ & & \\
Never chewed & 281 & 91.3 \\
Chewed & 27 & 8.7 \\
Cigarette Smoking: $\mathrm{n}=308$ & & \\
Never Smoke & 306 & 99.4 \\
Smoked & 2 & 0.6 \\
Hashish Use: & & \\
Never Used & 306 & 99.4 \\
Used & 2 & 0.6 \\
\hline
\end{tabular}

\subsection{Factors Related to Risky Sexual Behavior}

Logistic regression was carried out to check the effect of 
possible independent variables on risky sexual behavior and those variables, which have a p-value of less than 0.05 by multivariate logistic regression, were considered statistically significant. As a result, educational level $(\mathrm{P}=0.002)$, marital status $(\mathrm{P}=0.005)$, family marital status $(\mathrm{P}=0.003)$, living with whom $(\mathrm{P}=0.012)$ and alcohol consumption $(\mathrm{P}=0.042)$ were significantly associated with the development of risky sexual behavior. On the other hand, the other variables were not significantly associated with the development of risky sexual behavior.

Table 4. Association of variables with risk sexual behavior from study participants at TanaHaik Secondary and Preparatory School, February 2016.

\begin{tabular}{|c|c|c|c|c|c|}
\hline \multirow{2}{*}{ Variables } & \multicolumn{2}{|c|}{ Risky Sexual Behavior } & \multirow{2}{*}{ COR } & \multirow{2}{*}{ AOR } & \multirow{2}{*}{ P-value } \\
\hline & Yes & No & & & \\
\hline \multicolumn{6}{|l|}{ Sex } \\
\hline Male & 24 & 127 & $1.52(0.85-2.70)$ & $1.76(0.84-3.67)$ & 0.131 \\
\hline Female & 35 & 122 & 1.00 & & \\
\hline \multicolumn{6}{|l|}{ Age } \\
\hline $14-16$ & 22 & 111 & 1.00 & & \\
\hline $17-19$ & 37 & 138 & $1.35(0.75-2.42)$ & & 0.310 \\
\hline \multicolumn{6}{|l|}{ Education } \\
\hline Grade 9 & 7 & 101 & 1.00 & & \\
\hline Grade 10 & 25 & 57 & $2.1(0.69-6.33)$ & $4.2(2.11-15.94)$ & 0.002 \\
\hline Grade 11 & 20 & 43 & $0.33(0.13-0.83)$ & $0.79(0.26-2.40)$ & \\
\hline Grade 12 & 7 & 48 & $0.31(0.12-0.81)$ & $0.5(0.16-1.52)$ & \\
\hline \multicolumn{6}{|l|}{ Marital Status } \\
\hline Single & 45 & 245 & $19(5.99-60.52)$ & $8.5(1.9-8.55)$ & 0.005 \\
\hline Married & 14 & 4 & 1.00 & 1.00 & \\
\hline \multicolumn{6}{|l|}{ Family size } \\
\hline$<5$ & 15 & 78 & 1.00 & & \\
\hline $5-7$ & 40 & 144 & $0.77(0.23-2.52)$ & & 0.66 \\
\hline$>7$ & 4 & 27 & $0.26(.017-1.61)$ & & 0.26 \\
\hline \multicolumn{6}{|l|}{ Family Marital Status } \\
\hline Live together & 33 & 188 & 1.00 & 1.00 & \\
\hline Div/Wid/Sep. & 26 & 61 & $2.4(1.34-4.37)$ & $7.8(1.31-4.7 .2)$ & 0.003 \\
\hline \multicolumn{6}{|l|}{ Live with whom } \\
\hline With father and mother & 29 & 168 & 1.00 & & \\
\hline With Father/Mother & 5 & 38 & $12(5.20-28.46)$ & $1.2(0.19-7.22)$ & 0.012 \\
\hline With relatives/friends & 4 & 33 & $15.9(4.81-52.91)$ & $11(2.21-56.01)$ & \\
\hline Alone & 21 & 10 & $17(4.80-62.44)$ & $9.5(1.89-48.07)$ & \\
\hline \multicolumn{6}{|l|}{ Residence Situation } \\
\hline Live in the town & 39 & 214 & 1.00 & 1.00 & \\
\hline \multicolumn{5}{|l|}{ Father's Education: } & 0.693 \\
\hline Illiterate & 21 & 29 & $0.22(0.10-0.45)$ & $0.28(0.05-1.47)$ & 0.266 \\
\hline Primary education & 16 & 82 & $0.82(0.41-1.64)$ & $0.76(0.22-2.62)$ & \\
\hline Secondary and above & 22 & 138 & 1.00 & & \\
\hline \multicolumn{6}{|l|}{ Mother's Education: } \\
\hline Illiterate & 23 & 54 & $0.38(0.19-0.76)$ & $2.04(0.37-11.13)$ & 0.237 \\
\hline Primary education & 18 & 84 & $0.75(0.37-1.54)$ & $0.66(0.20-2.15)$ & \\
\hline Secondary and above & 18 & 111 & 1.00 & & \\
\hline \multicolumn{6}{|l|}{ Alcohol consumption: $n=308$} \\
\hline Never Drunk & 19 & 158 & 1.00 & 1.00 & \\
\hline Drunk (weekly/daily) & 40 & 91 & $3.6(1.99-6.68)$ & $2.22(1.03-4.37)$ & 0.042 \\
\hline \multicolumn{6}{|l|}{ Khat chewing: $\mathrm{n}=308$} \\
\hline Never chewed & 49 & 232 & 1.00 & 1.00 & \\
\hline Chewed (weekly/daily) & 10 & 17 & $2.78(1.20-6.44)$ & $1.4(0.46-4.37)$ & 0.542 \\
\hline
\end{tabular}

\section{Discussion}

Adolescence is the stage of life during which individuals reach sexual maturity. It is the period of transition from puberty to maturity. At the same time, adolescents are the greatest hope for turning the tide against sexually transmitted infections, AIDS, and early pregnancy because adolescence is a period of physical, social and emotional transition and development. This study attempted to assess the risky sexual behavior and factors that related to risky sexual behavior among high school adolescent students. Accordingly, the finding indicated that $26 \%$ of the participants were sexually active and that was consistent with a report from Pawi Wereda that showed $24 \%$ of the study participants were experienced sexual intercourse in their early age [13]. The finding revealed that adolescents were initiated to practice sex at their early age life, which points out the need to strength the life skill for adolescents. This may indicate that adolescents start sex at an early age, as a result, this exposes 
them to develop risky sexual behavior and its consequences. This finding was lower than the study findings from Bahir Dar University (36.4\%), Bahir Dar private colleges (42.3\%) and report from Russia (39\%) of participants were experienced sexual intercourse [14, 15, 16]. The variation may be due to that participant in these studies were more aged, live alone and exposed to many sexual risks in the Universities and colleges.

In this study personal pressure $(46 \%)$, peer pressure $(27 \%)$, forced (10\%), alcohol and chat influence $(9 \%)$ and economic problem $(9 \%)$ were the causes reported for the beginning of sexual practice. Likewise, a study finding from Oromia and Benishangul regions found that personal desire $(39 \%, 27 \%)$ and peer pressure $(23 \%, 16 \%)$ were the reasons reported for initiation of sexual intercourse respectively [17, 13]. This signifies that the influence to adolescents' action in their sexual relationship depends on many factors that lead them to practice risky behavior.

Having multiple sexual partners is one of the risky sexual behavioral factors that increase peoples' exposure to infectious diseases. In the current study, among sexually active respondents, $66 \%$ of them had one sexual partner; however, a significant proportion (34\%) of participants replied as they have two or more sexual partners. Our finding was consistent with the study done in Pawi Wereda high school students (35\%), Addis Ababa University students (37\%) and Tanzanian higher education students (39\%) [13, $18,19]$. This may point out that the risky behavior of school adolescents is high and needs attention to change their risk behavior.

Unprotected sexual intercourse is one of the major risk factors that expose school adolescents to risky sexual behavior. In the current study, $27 \%$ of school adolescents reported that they have never used the condom during their first sexual intercourse, which was better than a finding from Benishangul Gumuz (59\%) that showed the participants have never used the condom [13]. Low utilization of condom is an indication of the fact that high-risk behaviors are still widely practiced among high school adolescents.

It is known that substance use like alcohol, khat, and the cigarette was among the factors that pushed school adolescents to sexual debut at an early age. In this study, among those who had practiced sexual intercourse $9 \%$ of them reported that alcohol and chat influence were reasons for their initiation of first sexual practice. The more substances that school adolescents and young adults ever tried; the more likely they are exposed to risky practices.

Our study revealed that $19 \%$ of the study participants were developed risky sexual behaviors. Some of the reasons why respondents are at risk: $27 \%$ had sex without the condom, $34 \%$ had multiple sexual partners, and 5\% had sex with female commercial sex workers. In our study, the magnitude of risky sexual behavior was consistent with the finding from Pawi Woreda high school students $(20 \%)$ and slightly lower than the study finding from a private college of Bahir Dar city $(41 \%)[13,15]$. The discrepancy might be due to most private college students were living in a rented house away from their supervising families and they were elder than high school students to practice sexual behaviors.

Students who were in a higher educational level were about 4 times more likely to develop sexual behaviors compared to those who were in a lower grade (grade 9). Students, who were single, were about 9 times more likely to develop risky sexual behaviors than who were married. Students, who were living alone without their supervising families, were about 10 times more likely to have risky sexual behavior compared to those who were living with their father and mother and those students, whose parents were divorced, widowed and separated, were about 8 times have risky sexual behavior compared to students whose parents were live together. Students, who were drunk, were 2 times more likely to practice risky sexual behavior than who were never drinks.

\section{Limitations of the Study}

The study was mattered to limitations. The behavioral outcomes were based on self-reported information, which was subject to reporting errors and bias. Since the study was on very sensitive and private issues the possibility of underestimation cannot be ruled out. Since the study was based on cross-sectional data, which implies that the direction of causal relationships cannot always be determined.

\section{Conclusion and Recommendations}

A considerable number of school adolescents had started sexual activity early and have practiced risky sexual behavior that might predispose them to different sexual and reproductive health problems. Risky sexual behaviors were proven by use of condom inconsistently, having multiple sexual partners and having sexual intercourse with sex workers Delay in sex debut and reducing risky sexual behavior among adolescents can be achieved through well designed sexual education programs at the school.

\section{List of Abbreviations}

AIDS: Acquired Immunodeficiency Syndrome

HIV: Human Immunodeficiency Virus

\section{Declarations}

Ethics approval and consent to participate:

The study was approved by Ethical Review Committee of the Amhara Regional Health Bureau. Permission was also secured from Tana Haik secondary and preparatory school directors. Informed consent was obtained from each study participants and their parents (for $<16$ years old students). All participants were informed of their right to refuse at any timeand not to write their names to ensure confidentiality. 


\section{Consent for Publication}

Not applicable

\section{Availability of Data and Material}

The datasets used and/or analyzed during the current study are available from the corresponding author on reasonable request.

\section{Competing Interests}

The authors declare that they have no competing interests.

\section{Funding}

Funding was not received for this study.

\section{Authors' Contributions}

HA being the principal investigator contributed to proposal write-up, study design, data analysis, interpretation of results and write-up, MA being the co-principal investigator contributed in data analysis, interpretation of results and write-up, $\mathrm{AD}$ and NA had contributed to monitoring and supervision, data analysis and write-up, $\mathrm{MN}$ and $\mathrm{AG}$, had contributed to data collection, data analysis and write-up. All authors read and approved the manuscript.

\section{Acknowledgements}

First and foremost, we would like to express our deepest gratitude to Amhara Public Health Institute for supporting us different resources to conduct this study. We would like to also acknowledge the director and teachers of Tana Haik secondary and preparatory school for their cooperation during data collection. Last but not least, we would like to acknowledge students who participate in this study.

\section{References}

[1] International Planned Parenthood Federation. "Understanding Adolescents, in An IPPF Report on Young People's Sexual and Reproductive Health Needs," London. 1994. Available: http://www.plannedparenthood.org.

[2] United Nations, Department of Economic and Social Affairs, Population Division. World Population Prospects: The 2015 Revision.

[3] Z. Fekadu and P. Kraft, "Predicting intended contraception in a sample of Ethiopian female adolescents," The validity of the theory of planned behavior. Psychology and Health 2001; 16 (2): $207-222$.

[4] Child and Adolescent Health and Development. Adolescent sexual and Reproductive Health. Html 2004; 1-2.

[5] Ministry of Health. Rapid assessment on knowledge, Attitude and practices related to reproductive health in Ethiopia. Health education center and National office of population, Addis Ababa, 2000 Dec.

[6] F. Eshetu, D. Zakus, D. Kebede. The attitude of students, Parents and Teachers towards the promotion and provision of condoms for adolescents in Addis Ababa, Ethiop. J. Health Dev. 1997; 11 (1): 7-16.

[7] WHO. Programming for adolescent health and development. Report of WHO/UNFPA/ UNICEF study group on health programming for adolescents. Technical report series No. 886 . WHO, Geneva, 1999.

[8] L. Meschke, S. Bartholomae, R. Zentall. Adolescent Sexuality and Parent-Adolescent Processes. Promoting HTC. Family R. 2000; 49 (2): 143-154.

[9] Central Statistical Authority. Demographic and Health Survey. Addis Ababa, Ethiopia, 2005.

[10] E. Lemma. Predictors of HIV/AIDS related Sexual behavior of high school adolescents based on the classical health behavior models. Jimma Town, South West Ethiopia. (Unpublished Thesis Addis Ababa University), 2000 Dec.

[11] UNICEF, UNAIDS and WHO. Young people and, HIV/AIDS. Opportunity in crisis. Geneva. WHO, 2002.

[12] Reproductive Health Outlook. Adolescent Reproductive health: Overview and Lessons Learned. Available at: http;//www.rho.org/html/adol-overview.htm. Accessed 2015 Dec 11.

[13] Mulatu A, Tefera B, Tizta T, Muluwas A. Risky Sexual Behavior and Associated Factors Among High School Youth in Pawe Woreda Benishangul Gumuz Region. Sci. J. Cli. Med. 2015; 4 (4): 67-75.

[14] Wondemagegn M, Mulat Y, Bayeh A. Sexual behavior and associated factors among students at Bahir Dar University: a cross sectional study. Reproductive Health. 2014; 11: 84.

[15] Zelalem A, Melkamu B, Muluken A. Risky Sexual Practices and Associated Factors for HIV/AIDS Infection among Private College Students in Bahir Dar City, Northwest Ethiopia. ISRN Public Health. 2013; 9: Article ID 763051.

[16] Yuri A, Dennis VT, Jeffrey AK. Risk factors for HIV and other sexually transmitted disease among adolescents in St. Petersburg, Russia. Family Planning Perspective 2001; 33 (3): 106-112.

[17] I. Nassir. Factors that influences school adolescents exposure to HIV/STD in Bale, Oromia Region, 2006.

[18] R. Nigatu, K. Seman. Attitudes and practices on HIV preventions among students of higher education institutions in Ethiopia. Educational Research 2011; 2 (2): 828-840.

[19] E. S. Maswanya, K. Moji, I. Horiguchi. Knowledge, risk perception of AIDS and reported sexual behavior among students in secondary schools and colleges in Tanzania. Health Education Research, 1999; 14 (2): 185-196.

[20] A. M. Sunmola. Evaluating the sexual behavior, barriers to condom use and its actual use by university students in Nigeria. AIDS Care 2005; 17 (4): 457-465.

[21] Makwe E, Ahmad HA. Attitude, Sexual Behaviour, and Risk Perception to Sexually Transmitted Infections Including HIV/AIDS among Students of University of Abuja, Nigeria. British J. of Edu. Soc. Beh. Sci. 2014; 4 (3): 350-361. 